\title{
MODELING OF ECCENTRIC TRANSMISSION OPERATION IN PRESENCE OF ELASTIC DEFORMATIONS OF CONTACTING LINKS
}

\author{
P.N. Gromyko \\ Belarusian-Russian University \\ Mogilev, Republic of Belarus \\ grom_7@tut.by
}

\author{
S.N. Khatetovsky \\ Belarusian-Russian University \\ Mogilev, Republic of Belarus \\ mechlab@yandex.ru
}

\begin{abstract}
The paper considers plane and spatial (processional) eccentric transmissions and describes the procedure of their modeling. A computer analysis of the obtained models was carried out, which made it possible to evaluate the operating capacity in the absence and presence of elastic deformations of the contacting links.
\end{abstract}

Keywords - eccentric transmission; plane eccentric transmission; precessional transmission; elastic deformations of contacting link;kinematic error; efficiency.

\section{INTRODUCTION}

In designing power mechanisms for different applications, the choice of the type of mechanical transmission is an important issue. The attempt to minimize mass-dimensional parameters of the mechanical transmission in case of its operation under load inevitably leads to elastic deformations of contacting links, which considerably deteriorates the operational performance of certain types of mechanical transmissions.

Therefore, when designing new types of mechanical transmissions, it is important to establish the sensitivity of performance parameters to the elastic deformations of contacting elements.

Below, using as an example different types of eccentric transmissions, we show that by changing the structure and shape of gear teeth, it is possible to stabilize the performance parameters in the presence of elastic deformations of contacting links.

Theoretical assumptions regarding the possibility of minimizing the effect of manufacturing errors and elastic deformations of the links on the operational performance of eccentric transmissions are presented in $[1,2]$.

\section{PLANE ECCENTRIC TRANSMISSION SIMULATION}

Eccentric transmissions are small size transmissions with a coaxial arrangement of input and output shafts, which can transmit rotation within a wide range of gear ratios [3].

A plane eccentric K-H-V transmission, shown in Fig. 1, is the most known type of the eccentric transmission, its serial production having been launched by the world's leading firms [4].

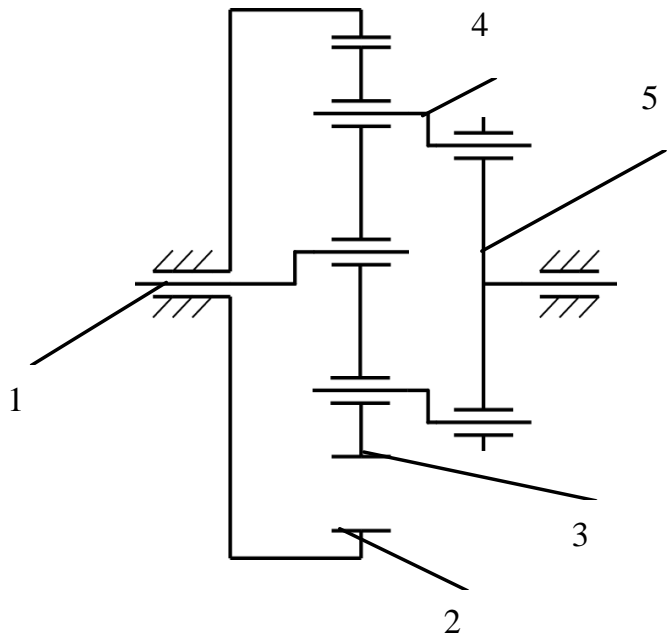

Fig. 1. Kinematic scheme of the plane eccentric transmission: 1 - input link; 2 - central gear; 3 - satellite gear; 4 - parallelogram mechanism; 5 output link

The methods of computer simulation in the Siemens NX $\mathrm{CAD}$ environment given below made it possible to determine the main performance parameters of the plane eccentric transmission under load, both in the presence and absence of elastic deformations of the contacting links.

A simulation scheme for the plane eccentric transmission is given in Fig. 2.

The input link 1 is fixed by means of a hinged immovable joint 2, which allows only the rotation with a constant angular velocity provided by an engine 3 (Fig. 2, a). A satellite gear 4 and an eccentric part of the input link 1 form a revolute pair by means of an elastic joint 5 , which is characterized by elastic coefficients based on the number of degrees of freedom (Fig. 2 , b). The displacements of satellite gear 4 with respect to the input link 1 are characterized by the elastic coefficients determined based on the values of forces in the transmission 
contact and the maximum possible elastic deformations of the links.

a)

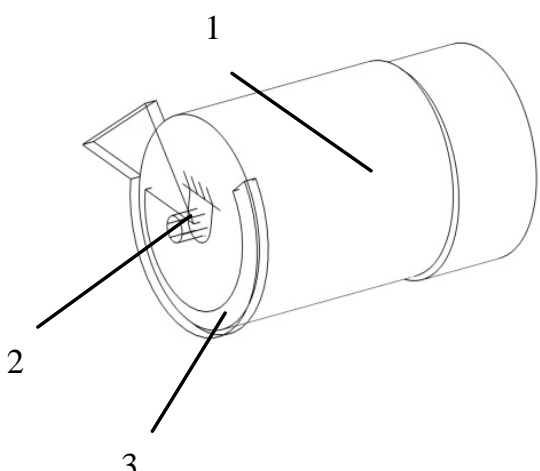

c)

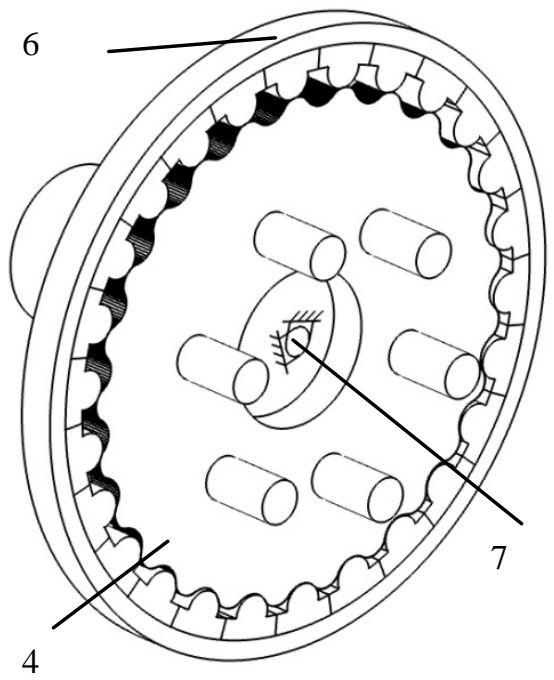

b)

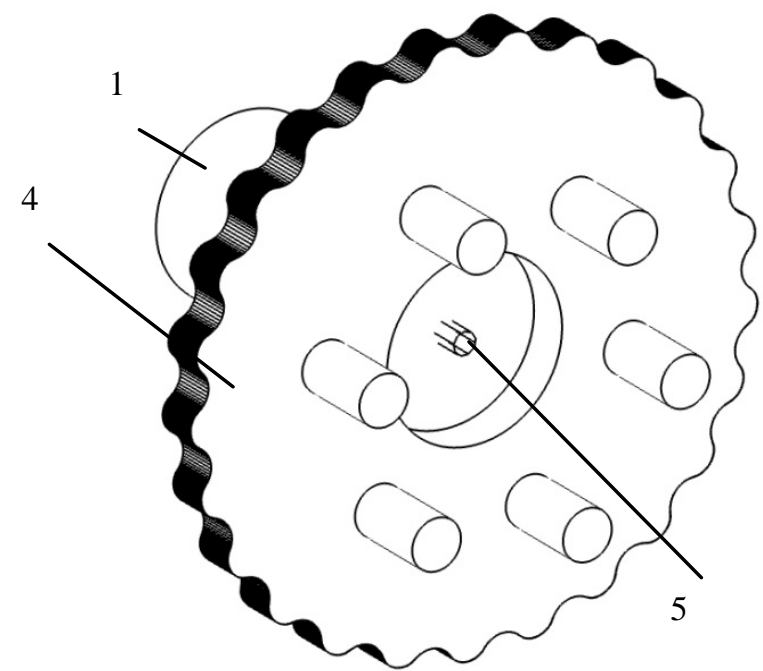

d)

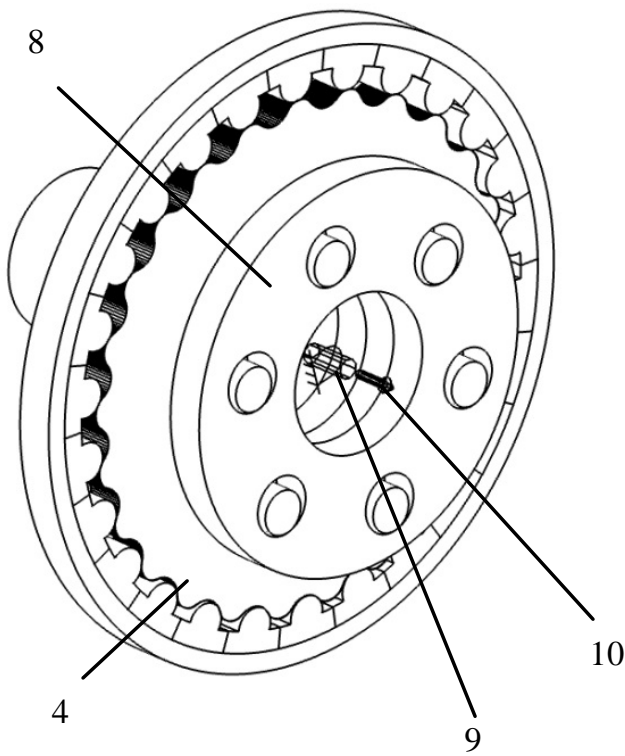

Fig. 2. Simulation scheme for the plane eccentric transmission: 1 - input link; 2 - hinged immovable joint ; 3 - engine; 4 - satellite gear; 5 - elastic joint; 6 central gear; 7 - fixed joint; 8 - output link; 9 - hinged immovable joint; 10- force couple

The teeth of central gear 6 fixed rigidly by means of a fixed joint 7 are in contact with the teeth of the satellite gear 4 (Figure 2, c).

The rotation from the satellite gear 4 is transmitted to an output link 8 by means of a contact element which is a parallelogram mechanism (Fig. 2, d). The output link 8 rotating about its axis is fixed by means of a hinged immovable joint 9 and loaded by a force couple 10 .
Fig. 3 and Fig. 4 show the graphical relationships between the main performance parameters of the plane eccentric transmission, namely, the kinematic error and efficiency, and the angle of rotation of the input link in the absence and presence of elastic deformations of the links.

The analysis of the graphical dependencies shown in Fig. 3 and Fig. 4 allowed drawing a conclusion that in the plane eccentric transmission the kinematic error increases sharply (from 5 to 18 angular minutes) and the efficiency decreases 
(from $87 \%$ to $56 \%$ ) in the presence of elastic compliance of links.

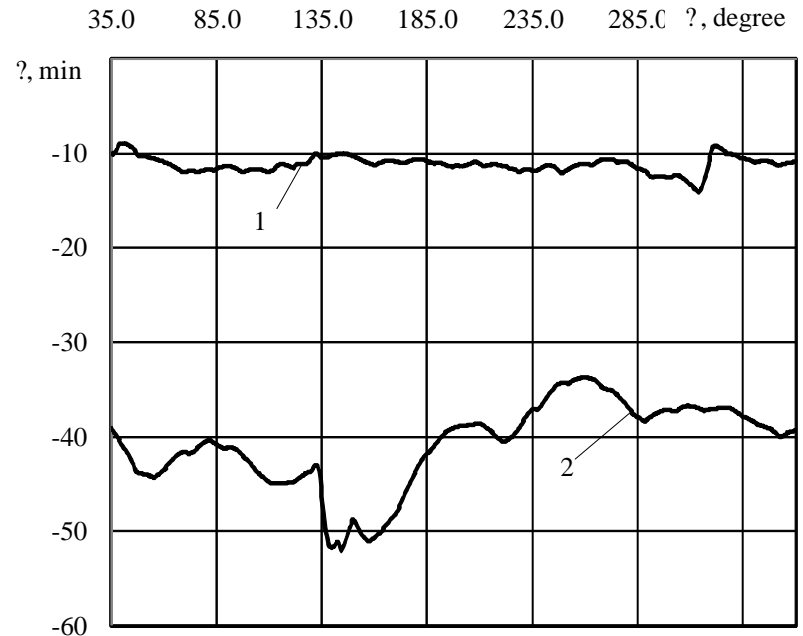

Fig. 3. Relationship between the kinematic error of the plane eccentric transmission and the angle of rotation of the input link: 1 without elastic deformations of the links; 2 -with elastic deformations of the links

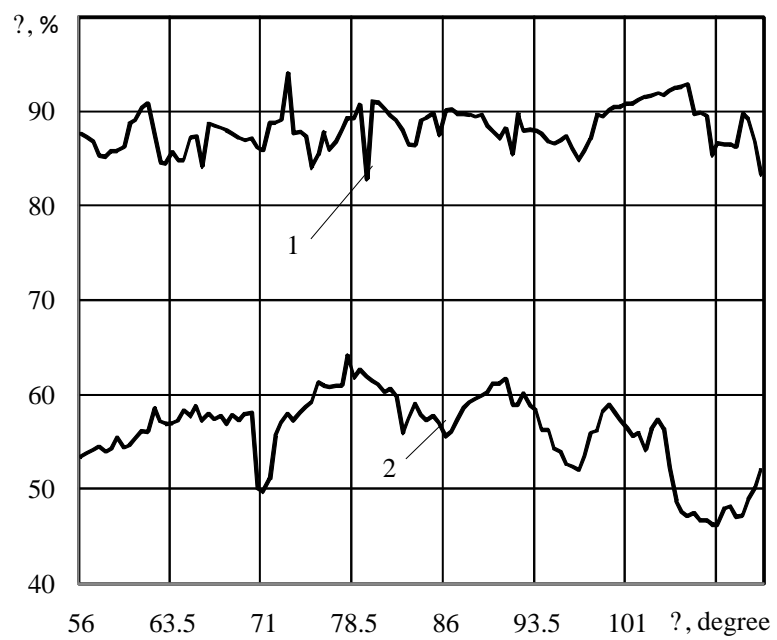

Fig. 4. Relationship between the efficiency of the plane eccentric transmission and the angle of rotation of the input link: 1 without elastic deformations of the links; 2 with elastic deformations of the links

Thus, relatively high performance parameters of the plane eccentric transmission can be obtained by minimizing elastic deformations of the contacting links, which can be achieved only by ensuring high precision manufacturing, as well as using special materials and technologies of chemical and thermal treatment. In its turn, this causes a significant increase in cost. Therefore, the high cost of the plane eccentric transmissions is the main factor that hinders their wide application in power mechanisms.

\section{PRECESSIONAL TRANSMISSION SIMULATION}

Another type of the eccentric transmission is precessional transmission. Researchers from the South Ural State
University [5, 6] and the Chisinau scientific school headed by Professor I.A. Bostan are investigating various types of the precessional transmissions $[7,8]$.

The reducers based on the structural version of the precessional transmission shown in Fig. 5 are being developed at Belarusian-Russian University [1].

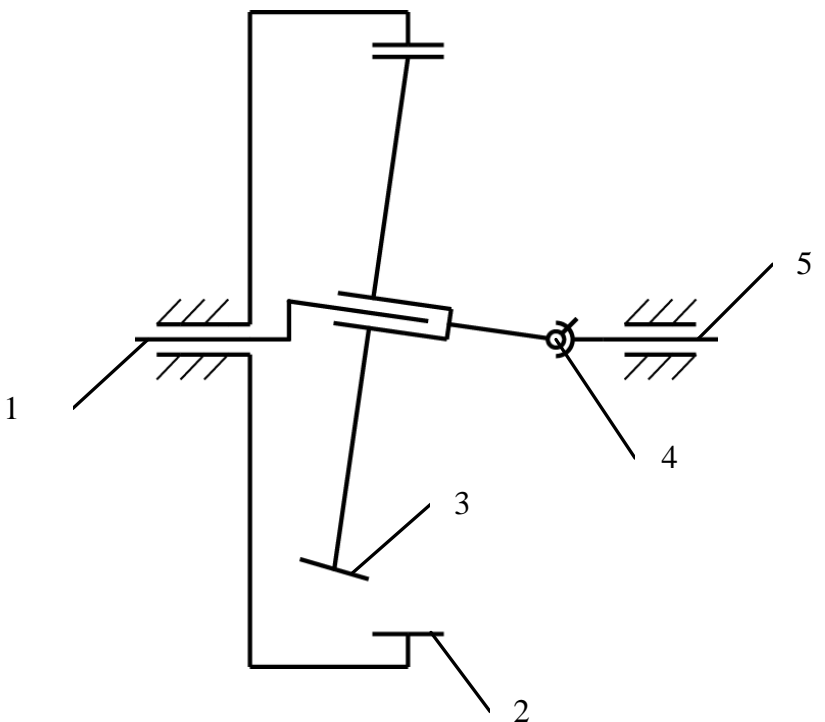

Fig. 5. Kinematic scheme of the precessional transmission: 1 - input link; $2-$ central gear; 3 - satellite gear; 4 - constant velocity joint; 5 - output link

A computer model was developed to study the effect of elastic deformations of links on the operational performance of the precessional transmission (Fig. 6). The input link 1 of the precessional transmission is fixed by means of a hinged immovable joint 2 and rotates at a constant angular velocity of an engine 3 (Fig. 6, a). A satellite gear 4 is capable of rotating relative to the inclined part of the input link 1 due to an elastic joint 5 (Fig. 6, b). The values of elastic coefficients of this joint are analogous to the coefficients of the plane eccentric transmission. The teeth of a central gear 6 , fixed rigidly by means of a fixed joint 7 , are in contact with the teeth of the satellite gear 4 (Figure $6, \mathrm{c}$ ). The rotation from the satellite gear 4 is transmitted to an output link 8 by means of a constant velocity joint 9 (Fig. 6, d). The output link 8 is capable of rotating about its axis due to a hinged immovable joint 10 and is loaded by a force couple 11 with a torque equal to that of the plane eccentric transmission (Fig. 6, e).

The graphs in Fig. 7 and Fig. 8 show the dependency of the kinematic error and efficiency of the precessional transmission on the angle of rotation of the input link.

We performed a comparative analysis of the graphical dependencies given in Fig. 7 and Fig. 8 and drew a conclusion that it is possible to build reducers based on the precessional transmission, whose kinematic scheme is given in Fig. 5. The operational performance of these reducers is characterized by a low sensitivity to elastic deformations of the contacting links.

The above-mentioned conclusion was confirmed by numerous bench, production and performance tests of the 
reducers designed based on the precessional transmission under consideration. To date, reducers with the precessional transmission have been introduced into drives of concrete

a)

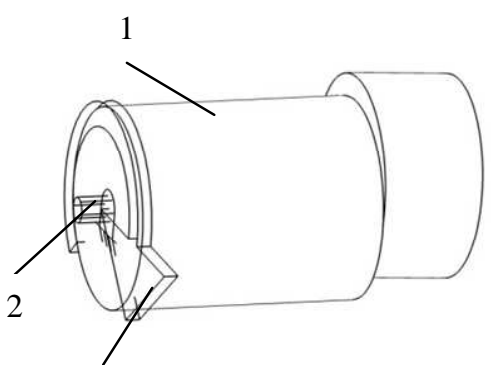

3

c)

4

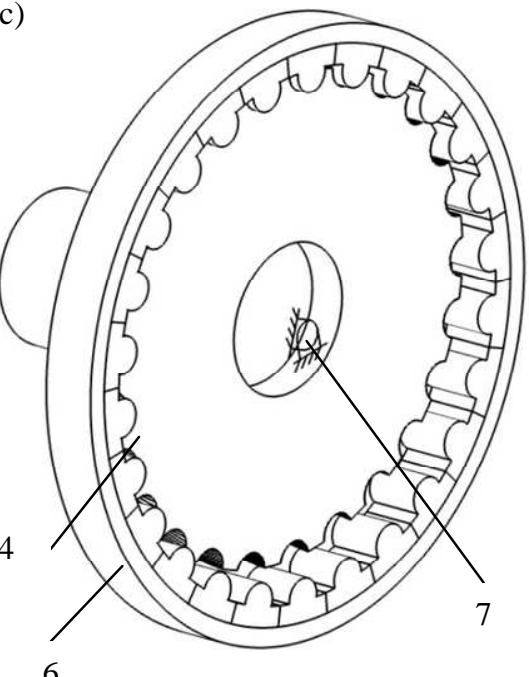

b)

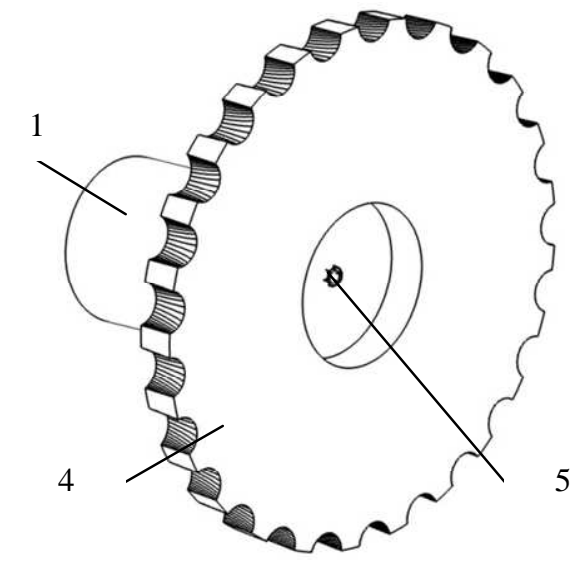

smoothing machines, grain drying equipment, screw conveyors and different lifting and tractive machinery.

d)
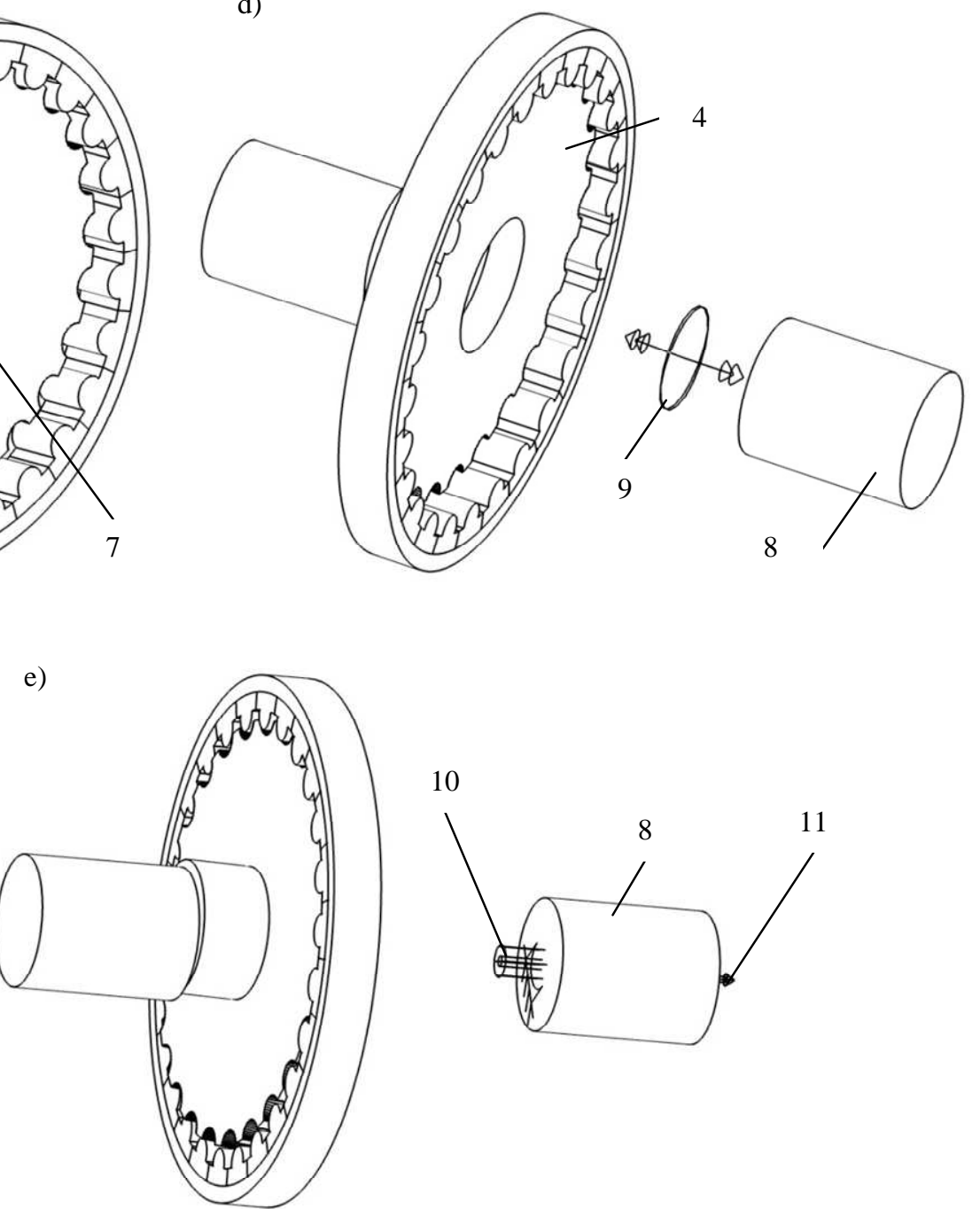

Fig. 6. Simulation scheme for precessional transmission: 1 - input link; 2 - hinged immovable joint; 3 - engine; 4 - satellite gear; 5 - elastic joint; 6 - central gear; 7 - fixed joint; 8 - output link; 9 - constant velocity joint; 10 - hinged immovable joint; 11 - force couple 
$\begin{array}{lllllll}35.0 & 85.0 & 135.0 & 185.0 & 235.0 & 285.0 & \text { फ. degree }\end{array}$

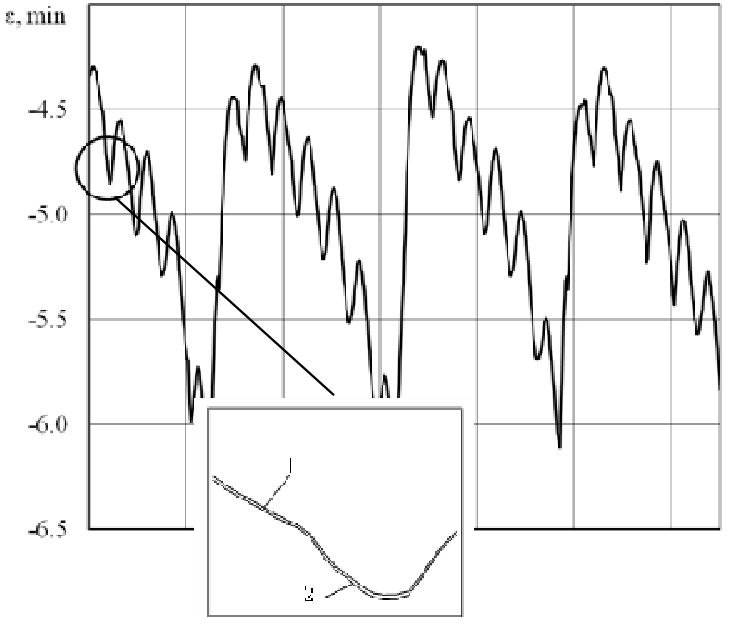

Fig. 7. Dependency of the kinematic error of the precessional transmission on the angle of rotation of the input link: 1 - without elastic deformations of the links; 2 - with elastic deformations of the links

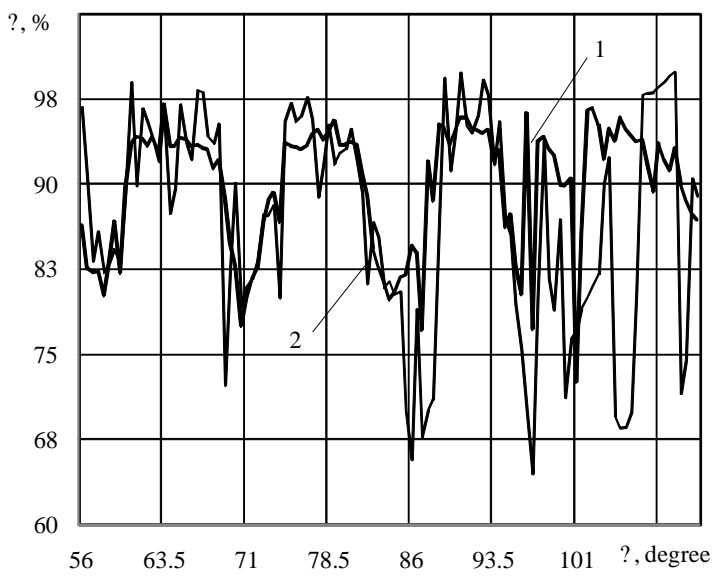

Fig. 8. Dependency of the efficiency of the precessional transmission on the angle of rotation of the input link: 1 - without elastic deformations of the links; 2 - with elastic deformations of the links

\section{CONCLUSION}

The results of the simulation of two types of transmissions - the plane eccentric transmission and the precessional transmission were compared and the conclusion was drawn that the precessional transmissions have a lower sensitivity of the main performance parameters, such as kinematic error and efficiency, to elastic deformations of the links that occur during operation under load. Therefore, there is no need to use special materials and technologies of chemical and thermal treatment in order to bring elastic deformations of contacting links in the precessional transmissions to a zero value, thus reducing their cost compared to the plane eccentric transmissions.

\section{References}

11] P.N. Gromyko, L.G. Dokonov, P. S. Hancharou, E. G. Krivanogova "Studies on the effect of elastic deformation of contacting units on the efficiency of planetary precession transmissions," Izvestiya NAN, Minsk, Vol. 3, pp. 66-70, 2012.

[2] S.N. Khatetovsky, P.N. Gromyko, et al. "Effects of errors in precessional transmission links on kinematic error," Vestnik BelorusskoRossiyskogo universiteta, Vol. 4, pp. 107 - 115, 2017.

[3] L.A. Borisenko, Small-Size Transmission Mechanisms for Mechatronic Devices, Mogilev, Belarusian-Russian University Publ., 2013.

[4] Catalog of coaxial motor reducers, OOO RedserviceTechno. Retrieved from: http://redservice.by/inline_gearboxes.html

[5] B.A. Lopatin, O.N. Tsukanov, Cylinder-Conic Transmissions, Chelyabinsk, YUrGU Publ., 2005.

[6] V.P. Eremen, N.V. Eremen, A.N. Kirilin, B.A. Lopatin, S.A Petrishchev, N.P. Rodin, V.M. Rublev, Y.N. Sekisov, The creation of a new generation of electromechanical wave drive gears of transformed systems of spacecrafts with long-term active existence, Samara, FGUP GNPRKTs TsKB-Progress Publ., 2011.

[7] I. Bostan, V. Dulgheru et all. Anthology of inventions, Planetary Precessional Transmissions. BonsOffices" SRL, Vol. 1, pp. 594, 2011. ISBN: 978-9975-4100-9-0.

[8] I. Bostan, V. Dulgheru "Development of planetary precessional transmission with multicouple gear," MeridianIngineresc, Vol. 4, pp. 7883, 2012. 